\title{
CALIDAD MÁS ALLÁ DEL PROCESO DE ENSEÑANZA
}

\author{
Lic. Juan Carlos García Pais*
}

Las instituciones educativas que no se han replanteado su rol tienen como única opción: pueden cambiar si quieren sobrevivir y progresar o pueden no cambiar si lo que buscan es quedar obsoletas y desaparecer. Esta imperiosa necesidad de mejora continua no implica necesariamente que las cosas se hagan mal, sino que quedan rápidamente descontextualizadas frente a las nuevas demandas externas, cada día más vertiginosas y exigentes, lo que lleva a un proceso de adaptación permanente.

El proceso de Calidad o mejora continua, recoge los principios de la Investigación - Acción por meio de los cuales, a través de un proceso reflexivo circular permanente, se comienza por planificar la acción contemplando la situación y el contexto, luego se ejecuta, después se comprueba y si no es totalmente satisfactorio se corrige; este círculo se repite ininterrumpidamente en la búsqueda constante de la excelencia. En ese proceso continuo, Aguerrondo (1995) nos plantea que la gestión eficaz de las instituciones educativas no pasa por administrarlas, sino por guiarlas hacia su transformación. Esta transformación requiere un modelo conflictivo de soluciones no tradicionales a problemas tradicionales, e implica una conducción dirigida hacia el mejoramiento de la calidad de la enseñanza a través del compromiso con el cambio constante y activo.

Aguerrondo sostiene que para solidificar el cambio, ese camino hacia la calidad debe girar en torno a tres ejes fundamentales: el epistemológico, el pedagógico y el social. En el eje epistemológico, la transformación pasa no sólo por la comprensión y explicación de los fenómenos desde una perspectiva clásica, sino también por la posibilidad de aplicar creativamente lo que se sabe para operar sobre la realidad actual. El proceso de enseñanza debe buscar el desarrollo del pensamiento crítico y creador en los alumnos; debe estimular la discusión y el intercambio de las distintas ópticas, no a través de la fragmentación de los núcleos conceptuales básicos de las distintas disciplinas, sino a través de la integración de los mismos. En el eje pedagógico, la transformación pasa por establecer una propuesta respetando las características propias de cada etapa de la vida del educando e integrando al docente en la toma de decisiones sobre la calidad de la enseñanza. En el eje social, la educación, además de la transmisión de valores básicos y de lograr el aprendizaje de conductas que posibiliten el desarrollo de una sociedad democrática, solidaria y participativa, debe brindar la formación en habilidades básicas para la incorporación del sujeto a la vida activa y su aporte científico para el desarrollo.

Aplicado el cambio y la mejora continua, sobre la base que plantea Aguerrondo, la institución desarrolla un conjunto de características propias y de su servicio que "aparentemente" satisfacen las necesidades de los consumidores y de los grupos de interés.

Decimos aparentemente porque la tarea aún no concluye; no se puede cometer el error de considerar que con la mejora en el proceso de enseñanza una institución obtendrá el reconocimiento social de servicio educativo de alta calidad. Se debe tener en cuenta que quienes juzgan y confieren la aptitud a una institución de satisfacer sus necesidades son los consumidores, ya sean estos internos o externos; las respuestas de ellos son las que mantendrán viva y competitiva a la institución, no la propia opinión de la organización. Mejorando los procesos de enseñanza y la participación docente, podremos llegar a obtener una enseñanza de alta calidad, pero esto no alcanza para obtener una calificación de servicio educativo de alta calidad a los ojos de quienes lo juzgan. 
Por esa simple razón, si lo que buscamos es un mayor apoyo a nuestro proyecto, para volcar recursos al desarrollo de una mejora constante en la calidad de la enseñanza y para lograr un mayor alcance en la extensión de nuestros servicios, debemos encarar otras acciones complementarias más allá del propio proceso de enseñanza.

En la educación, el consumidor intercambia un desempeño dirigido a la mente con resultado a largo plazo; por ello, la percepción de riesgo que tiene previo a la elección de un centro de estudios es mayúsculo y la decisión final queda limitada a la imagen que posee de las distintas instituciones. La imagen de la institución es el conjunto de creencias, ideas e impresiones que las personas tienen de la misma y le asignan un lugar en relación con las otras instituciones competitivas. Esta imagen se desarrolla a partir de la manifestación de dimensiones tan abstractas como la calidad del servicio educativo y su calificación por medio de atributos (satisfactorio, indiferente, insatisfactorio), lo que determinará la reputación en cada uno de los mercados vinculados a la institución.

La calidad percibida del servicio dependerá sobremanera de la calidad de la interacción entre el consumidor (padres y alumnos) y el prestador (institución). Como en el intercambio de servicios, la calidad depende además del usuario, del prestador del servicio y de la calidad del servicio en sí mismo; el cliente no sólo juzga los servicios por su calidad técnica, sino también por su calidad funcional. Si bien existen distintas opiniones al respecto, la calidad funcional del servicio es evaluada fundamentalmente desde tres dimensiones: confianza, empatía y tangibilidad.

Desarrollar y fomentar la confiabilidad implica destinar recursos para crear un ambiente favorable en la institución, donde todos sus integrantes estén consustanciados con el proyecto. La calidad la hace el ser humano, lo que determina que la capacidad, innovación e involucramiento de la gente que integra la organización sean claves para el éxito. Para desarrollar una cultura organizacional donde tanto el personal docente como el no docente, independientemente de su nivel y su función, esté consustanciado con el proyecto de centro, como primera condición, se necesitan líderes fuertes y apasionados por la perfección, ya que estos son el alma de una estrategia de servicios centrada en la confiabilidad.

El líder como impulsor del cambio debe asumir que nada es eterno; los valores culturales, la estructura demográfica, la economía, la política, la tecnología y la competencia, cambian. El escenario es distinto en cada contexto histórico; asumir estos cambios e internalizarlos para conocer el entorno en cada momento, es fundamental para prestar un servicio adecuado a las necesidades. Un papel clave de los líderes es dirigir las estrategias y apuntar el proyecto de centro a los cambios que se presentan en el campo de acción, siendo primordial la información para poder procesar éstos. Para efectivizar el cambio, es necesario desarrollar el concepto de cliente interno y relevar las necesidades del personal, alumnos y padres. Conocer la credibilidad del cliente interno en las propuestas de la dirección e informar y capacitar a todos los funcionarios de la institución, así como darles participación en las opiniones, recoger y discutir sus puntos de vista, es fundamental para lograr el involucramiento y compromiso del personal y contribuirá además a elaborar una única visión de centro compartida por todos.

Todos deben comprender el objetivo, el significado de la importancia de su trabajo y cómo se relaciona e interactúa con el trabajo de los demás. El trabajo en equipo y la fluidez de las comunicaciones interpersonales son elementos cruciales. La falta de comprensión, cooperación y comunicaciones, entre el personal, conspiran contra la confiabilidad y la construcción favorable de la imagen institucional. La visión de los funcionarios acerca de la identidad y de las fortalezas de la institución es crítica, ya que la construcción de la imagen comienza con la comunicación de los propios empleados del centro hacia fuera del mismo. Instaurar como filosofía de gestión la mentalidad de servicio en todos los funcionarios y actividades es una tarea imprescindible, para poder favorecer las comunicaciones internas y externas de la institución.

Generando el ambiente propicio, facilitaremos el desarrollo de nuevos servicios, lo que es clave para ubicarse como una entidad innovadora y a partir de las necesidades de los mercados. Son estos los que definen sus demandas, por lo que habrá que encontrar oportunidades y planificar y testear los

22 - Universidad ORT Uruguay 
nuevos servicios. Por ello deberemos estar alertas y atender tanto las necesidades implícitas como las explícitas de los consumidores y ser lo suficientemente proactivos como para responder a apetencias latentes que puedan marcar una diferencia a nuestro favor. Tengamos en cuenta que atender las necesidades implícitas solamente marcará nuestra discreta subsistencia, ya que aumentando el grado de cumplimiento de estas expectativas, no aumentaremos la satisfacción del consumidor, pero su incumplimiento hará que lo perdamos definitivamente (al elegir una institución los padres se preocuparan por servicios adicionales, pero darán por descontado que sus hijos aprenderán a leer y escribir). Sin embargo las necesidades explícitas y las latentes son las que determinan la elección y crean fidelidad. Las necesidades explícitas están compuestas por aquellas características del servicio que no componen su núcleo central, sino que se refieren a funcionalidades complementarias (que se enseñe idiomas e informática y se desarrollen actividades deportivas, artísticas y comunitarias); las expectativas latentes son aquellas que el cliente no manifiesta, porque no sabe que las tiene y al lograr determinados servicios la satisfacción aumenta rápidamente (nadie hubiera pedido educación a distancia hasta que apareció).

La confianza también se obtiene a través de no cometer errores, ya que las fallas ocurren en presencia del usuario; por lo tanto, cuidar todos los detalles para evitar estas circunstancias es vital. Pero cuando se cometen fallas, hay que tener capacidad de respuesta rápida; recordemos que un usuario presta más atención al desempeño cuando algo sale mal, por lo que es necesario iniciar las acciones correctivas tan pronto sea posible. Desde el punto de vista de la sicología social, los usuarios reaccionan con indiferencia ante los servicios de rutina, en cambio cuando se enfrentan ante una situación no rutinaria salen de la indiferencia y evalúan cómo la institución maneja esa situación; por ello tener en cuenta el factor molestia que tiene el usuario y esforzarse en resolver rápidamente los problemas logra efectos muy importantes a favor de la confiabilidad.

La empatía, como elemento sustancial, implica que el usuario sienta realmente que los representantes de la institución se ponen en su lugar y tratan de brindarle soluciones y no que le coloquen trabas o que le ocasionen molestias. Aunque el servicio esté estandarizado y se ajuste a los criterios de la correcta ejecución, en la medida de las posibilidades y sin caer en privilegios o inequidades, debemos contemplar la satisfacción de las necesidades del consumidor, por más subjetivo que este sea. Cuando lo que se evalúa en lugar de un objeto es esencialmente un desempeño, los requisitos del usuario se constituyen en el principal elemento de medición. Para transmitir confianza y empatía, es un elemento fundamental la creación de lazos estructurales con los usuarios. En un servicio de alta implicancia como la educación (dependiendo del nivel de enseñanza), los padres y alumnos necesitan relaciones continuas y personales con los representantes de la organización, quieren que estos representantes sean los que se preocupen por ellos y los conozcan. El terreno es fértil y las puertas ya están abiertas; consideremos que quien ya se acercó y optó por la institución, se compromete con la misma por el mero hecho de haberla elegido, por haber decidido por alguna razón, que el servicio de esta representa la mejor alternativa disponible a sus medios e intereses.

La base de esta proposición radica en que implica mucho menos esfuerzo enfocarse hacia mantener a los alumnos actuales y su núcleo, que asumir la pérdida de ellos y contrarrestarlo con nuevos alumnos; su propósito central es desarrollar usuarios que se alegran de haber escogido la institución, que perciben que reciben valor agregado y que además se sienten estimados. Si se logra esto, no solo se reduce sustancialmente la deserción, sino que además, padres, alumnos y exalumnos transmitirán información verbal favorable de la institución e incluso pueden estar dispuestos a asumir un costo extra por el beneficio que el servicio les reporta. Desarrollar el marketing de relaciones, además de lazos sociales y económicos, implica consolidar las relaciones con lazos estructurales, ya que el intercambio es fundamentalmente de corte emocional. Por lo tanto los esfuerzos que se realicen por forjar, cultivar y fortalecer la relación con padres, alumnos y exalumnos son pilares para lograr una formación y transmisión de imagen positiva hacia los distintos públicos. Estas relaciones crean un alto compromiso y al constituirse por sí mismas en servicios valiosos, se erigen como elementos no fáciles de imitar y marcan una ventaja competitiva fundamental en la imagen de una institución enfocada a la calidad. 
El servicio educativo, como los demás servicios, al no poder palparse, tocar, oler, ni probar antes de consumirlo, dificulta la elección del consumidor. Ante propuestas similares de ubicación, religión, precio y extensión del servicio, el consumidor dispone como únicos factores de elección la propia experiencia pasada (si la tuvo), la recomendación de referentes confiables y la visualización de elementos que le ayuden a terminar de construir la imagen de cada institución. Frente a esta situación, y considerando que no hay imágenes sin objetos, a través de la tangibilización del servicio, la institución educativa debe contribuir a brindar al consumidor los suficientes elementos visuales que contribuyan a construir la imagen.Se deben establecer pautas de estilo congruentes con la imagen que se quiere transmitir, que determinarán todos los aspectos de la recepción y atención al público: desde el logotipo, los elementos de identificación externa, la señalización interna, los uniformes del personal, las tarjetas de presentación personal, las características del papel, formularios y sobres, el diseño y decoración de las instalaciones, hasta el lenguaje de atención.

Un buen ambiente es un ambiente cálido, por lo que no se deben descuidar la estética de los locales, que debe llamar a entrar; la higiene e iluminación que deben ofrecer seguridad y confianza; tampoco se puede descartar la animosidad que brinda una música adecuada. Es importante también disponer visiblemente de materiales y equipamiento complementario que ayudan a la prestación de un servicio de alta calidad, como computadores, televisores, proyectores, etc., que dan la idea de una puesta al día tecnológica, sin descuidar las bibliotecas completas y funcionales.

Teniendo en cuenta que el primer contacto del público con la institución es crítico, porque solo hay una oportunidad para causar una primera buena impresión, se pueden estandarizar los estilos de lenguaje para la atención personal o telefónica del público, capacitándose al personal a esos efectos, lo cual contribuye a otorgar homogeneidad y calidad de servicio. Consideremos que en un nivel donde las cosas son lo que no parecen, el lenguaje juega un rol muy especial; capitalizar el lenguaje implica esforzarse por interpretar lo dicho y lo no dicho por los consumidores; recién a partir de ello hay que construir lo que se debe decir y lo que no, por parte del personal. El lenguaje construye relaciones y vínculos, conocer lo que vincula a un consumidor con un servicio marcará el la ubicación apropiada y trasmitirlo eficazmente a través de una propuesta que exponga claramente los beneficios en una forma exclusiva y atrayente, contribuirá al éxito. En definitiva, el entorno con sus elementos materiales e inmateriales debe convertirse en una invitación a desarrollar de la manera más eficaz, íntegra y agradable los procesos de enseñanza y aprendizaje.

Resumiendo, una gestión orientada hacia la Calidad Total se basa en tener como norte la satisfacción del consumidor en todas sus dimensiones, la mejora continua, la participación y el desarrollo del personal, y fundamentalmente una visión que apunte hacia fuera de la organización en la búsqueda de resultados a largo plazo. Cuando se adopta la postura de que la organización está formada por fuerzas relacionadas, se pueden crear organizaciones con capacidad de aprender, en las que las personas amplían constantemente su competencia y existe una aspiración colectiva al aprendizaje constante, donde existen visión y valores compartidos. 


\section{Bibliografía.}

AGUERRONDO, I. 1994 El planeamiento educativo como instrumento de cambio. Buenos Aires: Troquel.

BRASLAVSKY, C. 1990 Conducción educativa y calidad en la enseñanza media. Buenos Aires: Miño y Dávila.

CARR, W. 1997 Calidad de la enseñanza e investigación-acción. Barcelona: Díada.

FRIGERIO, G. y otros. 1995 El sistema educativo como ámbito laboral. Buenos Aires: Universidad de Buenos Aires.

MANES, J. M. 1997 Marketing para Instituciones Educativas. Barcelona: Granica.

* Lic. en Administración y Diplomado en Educación. Especialista en Marketing educativo. 